\title{
Community-Led Sanitation in Simoonga, Zambia
}

\author{
Maggie McDaniel \\ Senior, Mechanical Engineering \\ University of Virginia \\ mags.mcdaniel@gmail.com \\ Robert Swap \\ Professor, Department of Environmental Sciences \\ University of Virginia \\ rjswap@gmail.com \\ Dillon Chapman \\ Senior, Spanish and French \\ University of Virginia \\ dfc4t@,virginia.edu
}

\author{
Emerson Prebil \\ Senior, Systems Engineering \\ University of Virginia \\ eap4v@,virginia.edu \\ Caroline Berinyuy \\ Doctoral Student, Curry School of Education \\ University of Virginia \\ cmb9tf@,virginia.edu \\ Hallie Eilerts \\ Junior, Global Development Studies and History \\ University of Virginia \\ hce6f@,virginia.edu
}

\author{
Jack McDaniel \\ Sophomore, Finance \\ University of Georgia \\ jmcd2222@uga.edu
}

Abstract - This paper describes a sanitation project conducted by students from the University of Virginia and the University of Georgia. The authors describe their collaboration with a network of partners in Zambia to design and build communal latrines. The process of project development is presented including project scope and team building both at UVA and with the partners in Zambia. The paper discusses researching rural latrine designs and the preliminary construction of a prototype in Charlottesville. The authors examine the processes of community engagement in Simoonga and the strategies for bringing together the UVA team and the network of local partners. The paper outlines the iterative design and construction process as well as a discussion of project challenges, resolutions, results and lessons learned. This includes the overall goal of undertaking these processes while staying true to the community-led approach, where the community members themselves are empowered to collaborate on the project. The team strove to implement a project attuned to local realities and powered by local people and resources. Furthermore, it was the team's hope that such a project would continue to inspire positive community initiatives beyond its completion in July of 2010.

Index terms - rural latrines, communal latrines

\section{INTRODUCTION}

Lack of proper sanitation is a significant worldwide health issue. UNICEF estimates that 2.5 billion people, constituting almost 50 percent of the world's population, lack access to basic sanitation. Millions among these people contract water-related diseases that could be prevented by basic measures to improve water sanitation. Access to improved sanitation is lowest in SubSaharan Africa, where only 36 percent of the population has regular access to improved 
sanitation, leaving the other 64 percent in unsanitary and therefore unsafe conditions. ${ }^{\text {ii }}$

This project addresses the issue of sanitation at a local level in Simoonga, Zambia. A US student team responded to an expressed need for sanitation improvement within the community. The outcome was a community led initiative in which the students entered into a mutual learning experience with their partners. The collaboration combined perspectives gained from institutional educational opportunities with local expertise, experience, and existing capacities. Together, the student team and the community partners built two ventilated improved pit latrines (VIP) and established a Sanitation Committee to promote and encourage improved sanitary practices within the community.

\section{Project BaCKGRound}

The village of Simoonga is a rapidly growing rural village of 1,500 people, located in Southern Zambia. Historically, this region of Sub-Saharan Africa, possessing "deep fertile soils along the beds of major rivers," has typically been home to farming communities. iii Setting down roots in one place for agricultural purposes led to the establishment of villages. Theses villages often gave rise to tight-knit and highly regulated communities "in which everyone's status was clearly defined, including women and men, chiefs and commoners, and elders and youth"iv. Learning about the region's history influenced our team's expectations of the village. Upon arriving in Simoonga, some of these were confirmed while many other prior assumptions about the village were disproved.

The village lies approximately $20 \mathrm{~km}$ from Livingstone, Zambia which, given its proximity to the mighty Victoria Falls, is a popular tourist destination. The proximity to Livingstone has affected the village greatly. Few residents make their livelihood on agricultural practices. Local sources have maintained that over the past decades, satellite communities outside of Livingstone, such as Simoonga have shifted the emphasis of their economies from a self-subsisting agrarian economy towards one almost entirely based off of servicing the tourism industry and the needs of local tourist lodges. Most villagers either find work at one of the many upscale tourist lodges along the Zambezi River or in Livingstone town itself. There is little opportunity for formal employment within Simoonga.

With this shift away from agriculture, the village increasingly became home to new residents, who were moving from deeply rural settings to the outskirts of Livingstone in search of employment. These newcomers were not necessarily looking to live on large plots of land, but instead looking for work in and around Livingstone. Simoonga began to resemble a collection of individuals, living together to satisfy individual needs rather than community needs. As opposed to the close-knit, "interdependent" village community described as being traditionally African, Simoonga was a virtual melting pot of people from all across the country. Few residents were brought to Simoonga by familial ties that extended past the previous generation. A shared sense of history or tie to the community itself was not very pervasive.

Our team underestimated the impact of the tourism industry on Simoonga in other ways as well. We came to learn much about the type of relationship that had developed between those leaders in the tourism industry and local leadership in Simoonga. Through a deal with at least two local tourist lodges, parts of the village itself can be toured by guests who are curious to have an "authentic" experience in an African village. After such tours, guests often make monetary donations to special village funds. These funds, maintained by some of the lodges, 
along with other initiatives by various NGOs in the area, and some private ventures, have prompted a number of development projects in the village. These projects included the construction of a town hall, concrete Ventilated Improved Pit latrines at Simoonga Basic School, and boreholes with pumps throughout the village. Still, in learning about these initiatives and Simoonga's relationship with the parties that were responsible for them, many surprises still lay ahead.

One such surprise involved the distribution of resources throughout the village. For instance, the fuel allotment for the borehole pumps prioritized one side of the village over the other. This was the side of the village where the village Headlady lived. Courting a much closer relationship with the tourist lodges, the Headlady's side appeared to be better positioned to benefit from their donations. The team found this to be a point of contention with those who live on the Headman's side of the village. Our team had learned of these two leaders prior to our arrival, but little about the inequalities between their respective sides or their tenuous relationship.

The existence of two leaders also came as somewhat of a surprise to the team as it was indicative of an untraditional African village leadership structure. Furthermore, certainly the village Headlady and Headman were two respected elderly leaders; however, the village was also attempting to incorporate a new structure, the village council, consisting of members picked by a local NGO. Half of these members came from each side of the village, six males and six females. Most members of the council were in their thirties, some were as young as twenty-five or as old as fifty-eight. The team knew of the council prior to arrival, but did not know that this structure had only been transplanted only a year before and was still struggling to define its role within a divided community. Thus, when initially designing a project with Simoonga in September 2009, there was still much to learn about the village.

In the summer of 2006, a student team member from the University of Virginia visited Simoonga as an ecotourist. In the process, this student established and maintained contact with the managers of a tourism fund that implements projects within the village. Having been moved by his experience in Simoonga, this student, upon his return to UVA, created a Contracted Independent Organization (CIO) student group for Simoonga's benefit. Students involved with the CIO fundraised to improve access to secondary education by providing transportation for Simoonga students to Livingstone. In 2009, as the relationship between the UVA CIO and the village of Simoonga continued to grow, village leadership identified improving the village's sanitation as their top priority. From this relationship, so began the team's work to learn more about the village of Simoonga, strengthen personal and professional ties to, and begin preparing for a trip to Zambia in the hope of partnering with the village to address their sanitation goals.

\section{BUILDING RELATIONSHIPS}

\section{Forming a Student Team}

The student team developed within the framework of two different semester long courses, focusing on engineering in community settings and global development on the ground. One of the primary means of developing the student team was the construction of a prototype at a local camp. During the spring semester, the team worked with a community partner at the camp to design a latrine fitting the environmental and usage needs of the camp. At this point, the student team expanded to include a landscape architecture student from the University of Georgia in 
order to add to the already varied perspectives present within the team. In building the prototype, the team learned to work together as a single unit to work with and for a community stakeholder. Dealing with unexpected challenges in this setting taught the student team to work together as a unified team whenever problems arose.

\section{Developing Relationships with Partners on the Ground}

As had been impressed upon the students both in and outside of class, it is important to begin the process of engagement early on in development projects. In this case, starting early involved identifying stakeholders and beginning to cultivate stronger relationships even from abroad. The students corresponded extensively via phone and email with the managers from a local lodge, employees of an NGO, and with a Simoonga Village Council Member. These interactions no matter how brief or in what form, provided opportunities to share goals and exchange ideas with the larger community. And it was this history of communication that served as a foundation for strengthening relationships upon the team's arrival.

From these series of conversations and discussions, the students learned that the village was working with an employee of a United States Agency for International Development (USAID) program to apply for funding to construct new latrine/bathing structures, under the supervision of a local NGO with strong ties to Simoonga. They connected with a deputy from the USAID program, who was enthused by their interest. The students then continued to develop relationships with various employees of the local NGO during the seven months before departing for Zambia, and, upon arriving in Lusaka, the capital, met these contacts at the USAID program's headquarters. It is the connection that will facilitate access to the village.

\section{Preparations for LATRine CONSTRUCTION}

\section{Evaluating Design Alternatives}

While the students developed relationships with Zambian partners from abroad, they also researched various latrine designs. The examined literature included sanitation reports written by international institutions ${ }^{\mathrm{vi}}$, global development organizations (GDOs) ${ }^{\mathrm{vii}}$, state governments ${ }^{\mathrm{vii}}$, and other project teams ${ }^{\text {ix }}$. Criteria for evaluating potential solutions included construction requirements, relative cost, and upkeep requirements. (See Table 1)

TABLE 1

Product Design MATRIX FOR LATRINe Design SELECTION

\begin{tabular}{|c|l|}
\hline Requirements & \multicolumn{1}{c|}{ Importance } \\
\hline $\begin{array}{c}\text { Building } \\
\text { Requirements }\end{array}$ & $\begin{array}{l}\text { Local volunteer labor including building experts, safe } \\
\text { structure/slab, pit below water table }\end{array}$ \\
\hline $\begin{array}{c}\text { Material } \\
\text { Requirements }\end{array}$ & $\begin{array}{l}\text { Obtain local materials when possible, quality for } \\
\text { stability/permanence without overextending budget }\end{array}$ \\
\hline $\begin{array}{c}\text { Relative } \\
\text { Cost }\end{array}$ & $\begin{array}{l}\text { Least expensive option possible while accomplishing } \\
\text { other requirements, no labor cost, minimal transport }\end{array}$ \\
\hline $\begin{array}{c}\text { Upkeep } \\
\text { Requirements }\end{array}$ & $\begin{array}{l}\text { Permanent structure intended to last for 10+ years } \\
\text { with minimal, inexpensive maintenance \& upkeep }\end{array}$ \\
\hline
\end{tabular}


After evaluating the initial criteria, the students chose three designs to further investigate: the composting and urine diversion (UD) toilet, the aqua privy and soakaway toilet, and the Ventilated Improved Pit (VIP) toilet. Each technology is described below. (See Fig 1).

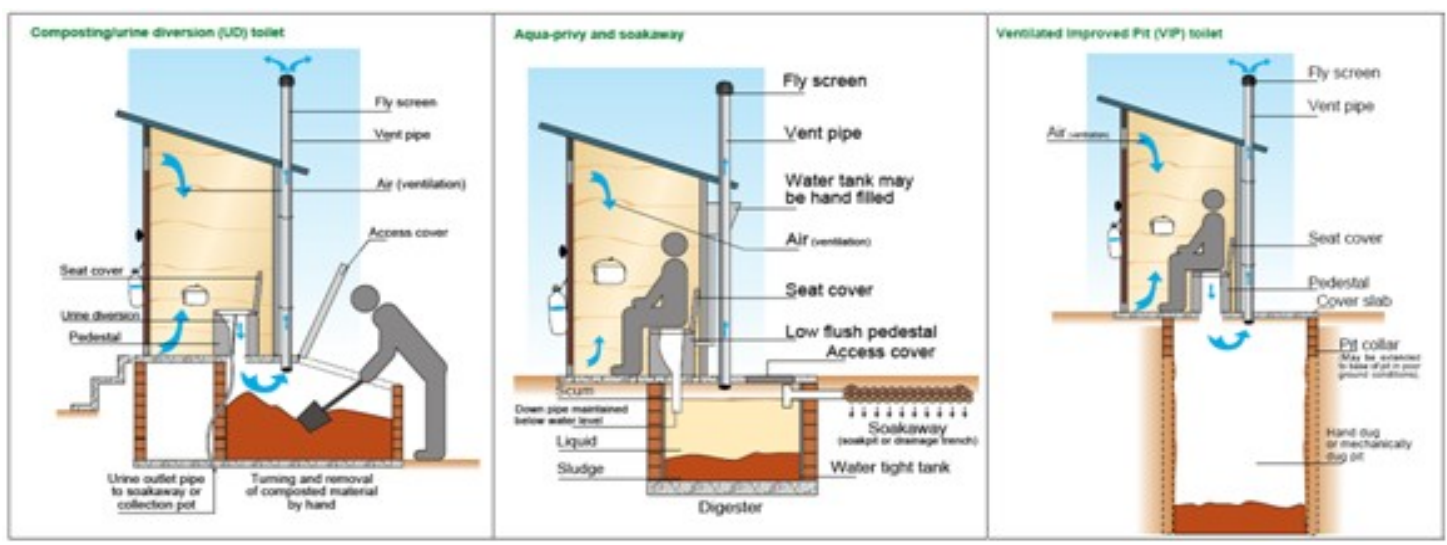

FIGURE 1

ALTERNATIVES CONSIDERED FOR LATRINE ${ }^{\mathrm{X}}$

A UD toilet divides the urine and feces into separate containers. The urine is captured and diverted by means of a tube or pipe into a soakaway pit. Fecal matter collects in a pit which can be accessed from the outside. Dry absorbent material can be added after each use to deodorize and aid in reducing moisture. In the absence of the increased moisture and sterilizing effect of urine, the environment of the pit enables effective composting. The upkeep of a UD toilet would require manual turning and removal of the composted waste. Because the design channels urine and waste to be collected separately, the system might not function properly if the urine diversion cup falls or malfunctions in another way. Because first time users might be confused by the urine diversion component, extensive replication of the toilets could be difficult. In addition, the UD toilet is the most expensive of the three options considered.

An aqua privy and soak-a-way toilet consists of a structure placed above a water-tight tank. Waste from the toilet travels into the tank below through a chute. A few liters of water are used to flush down waste. This addition of water also keeps the water level in the tank high enough for the end of the chute to be submerged. Waste falls to the bottom of the tank and is entirely submerged in water. As the two mix and dissolve, a sludge layer forms on the bottom while a liquid layer forms on top. When the tank is full, liquid is able to dissipate out through a soakaway. This soakaway is well above the water table. The water required for flushing can be carried by hand to the toilet. Waste that solidifies at the bottom of the tank must be emptied mechanically. Subsequent treatment and disposal of the solid and liquid waste depends on the resources of the community. If not properly used and maintained, this latrine design can easily malfunction due to blockages of the chute or overflow. The structure is relatively easy to build; however, it is only appropriate in conditions with a low water table where the earth is dry enough for a soakaway approach to be effective. Additionally, there must be enough available water to justify its use in a flush system. The aqua privy and soakaway toilet would cost more than a VIP latrine but less than a UD toilet.

The VIP toilet is comprised of a large pit and a structure above the pit. The structure has 
a sitting or squatting area, a vent pipe rising from the pit, and a fly screen above the vent pipe. Waste drops down into the pit where organic materials decompose. The vent pipe exists to increase airflow through the pit. Air flows down through the interior hole, aerates the decomposing fecal matter, and travels up through the ventilation pipe. This dramatically improves the smell traditionally associated with long drop pit latrines. The fly screen atop the pipe aids in fly reduction. Flies are drawn in to the pit towards the decomposing matter. When they attempt to exit, they are drawn towards the light at the top of the pipe. However, the fly screen traps flies in the pipe, and they are unable to escape. This small measure reduces spread of fecal germs via insect. As with the aqua-privy and soakaway toilet, a VIP latrine is only appropriate in conditions with a low water table where the earth is dry enough for a soakaway approach to be effective. When the pit becomes full, which could be every 1-5 years depending on the pit size, the pit must either be emptied or closed for use. The VIP structure is fairly easy to build, is the least expensive of the three options, and has seen recent success and popularity in Sub-Saharan Africa.

The team, village council, and partners from a local NGO concluded that the VIP latrine design was the most practical option to be implemented in Simoonga. The VIP had the lowest estimated cost and was the easiest to implement. Existing latrines were variations of the VIP latrine design, which indicates that the design was familiar and acceptable to villagers. The VIP design was selected with the intention of being flexible and easily adjusted in accordance with changing stakeholder needs.

\section{Prototype Construction}

After researching various designs, the student team built a prototype latrine at a local camp. The students and camp stakeholders worked together to design a latrine that would meet the needs of the camp, test design principles, and give the team practical construction experience. (See Fig 2) Unlike the structures to be built in Simoonga, this latrine was constructed primarily out of wood, was built above ground, and had toilet seats and covers. As an establishment that valued environmental education, the camp desired a composting toilet that could be easily maintained while exhibiting common composting practices. The latrines would also service a mountain campsite with a fairly rocky terrain. In light of this, the structure was designed to hold waste in large removable plastic containers rather than in an underground pit. The containers could be removed from the structure so that waste could be transferred to larger composting sites. The containers would then be placed back underneath the seats. This design used concrete to hold wooden frames in place. Concrete was an essential material in building the latrine in Zambia, thus this prior experience working with concrete proved useful. 

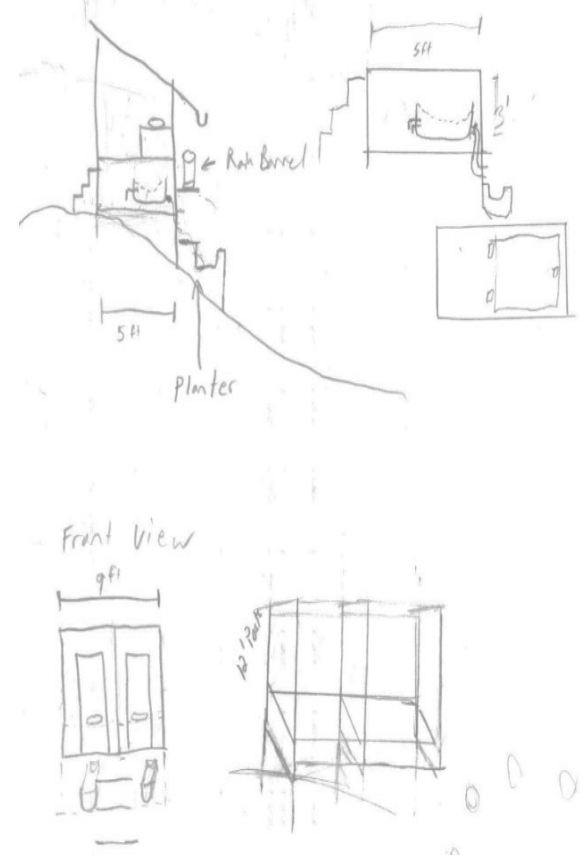

FIGURE 2

\section{Preliminary Design of Prototype Latrine (Drawn by Mike Bruscia of Triple C} CAMPS)

The camp requested that the latrine be built at a campsite at the top of a hill, which posed issues during construction but taught the team valuable lessons. The students had initially planned on using a truck to transport the building materials, but the truck was unavailable for two weeks. Manually transporting all building materials up the hill required a great deal of time, so the team could not actually start building the structure until much later than they had anticipated. Once the truck became available, construction progress increased considerably. Overall, construction took four weeks, which was much longer than expected. Through this experience, the team learned the importance of expecting delays and being able to adapt to setbacks. This experience was one factor that led the student team to refrain from setting a strict building schedule or target number of latrines before arriving on the ground in Zambia. A flexible timeline better reflected the fact that a great deal of time would be spent engaging the community. The team hoped to make this engagement a priority while still expecting that construction delays were likely and that the overall process could take longer than expected.

The experience of building a prototype helped solidify team dynamics. The students encountered differing project approaches and had to adjust to working and interacting with one another. By testing patience, prioritizing, and learning different ways of resolving challenges, the students developed a range of approaches to compromise and work through solutions together. The team experienced a variety of challenges related to conducting student team service learning projects in a 'real world setting.' Rather than viewing these events problems or impediments, the team saw these situations as an opportunity to build team problem solving skills during the prototype building process. Perhaps one of the best outcomes of the prototype 
build out experience was that the students were able to approach problems as a team.

The team also benefitted greatly from the experiences gained working with the local camp where the prototype was built. The Experiential Education Director had extensive knowledge of sanitation and latrines and better understood the camp's needs and potential solutions to meet those needs. The students understood this, and recognized that their role was to listen, learn, interpret, and design to the client's specific needs. The importance of not imposing ideas on the client was a valuable lesson for the students to learn. The students also realized the importance of clear and constant communication, maintaining positive relations, and flexibility. They practiced problem-solving skills to adjust the original plan in order to save time, money, and effort without compromising quality of the latrine they intended to build. Interacting with the camp prepared the team for work in Zambia, where locals also had expertise and a better understanding of their own needs.

\section{PROJECT IMPLEMENTATION IN ZAMBIA}

\section{Establishing a Collaborative Environment}

Of the many construction oriented development projects that have been implemented in Simoonga, few have asked much of the community. Instead, donors have most often given money to the charity funds which hire contractors to carry out various initiatives. Many structures have been built in Simoonga as a result of these initiatives. Some of these structures include the previously mentioned community hall, six concrete pit latrines at the basic school, a police station, and a preschool. With little incentive to contribute to any of these efforts, the people of Simoonga do not value the gifts as products of their own labor. The structures often fall into disrepair as community members expect the donors to take care of the project they commissioned, and the donors expect Simoongans to take on the projects as their own property once completed. Bendetta Rossi writes that such a dynamic reinforces the "roles" of "giver" and "recipient" with cyclical short-term solutions, allowing for both actors to play their part in "reproduc[ing] development rationalities" donations for what Nyamu-Musembi call their "quantifiable outcome" rather than the practice of a more "participatory development" that puts "values and politics at the very heart of development practice"xii. A prime example of this was the town hall which was built and donated to the village in 2009. The roof was blown away by a storm but had not been repaired in the four months that had passed since the incident. The villagers claimed they had no money to do so, while the donors no longer viewed the hall as their responsibility.

The team wished to assist in a project that did not follow in the footsteps of those that had come before it. Beginning by reaching out to Simoonga, and addressing a desire to work with the village on an initiative of their choosing, a "community-led" initiative, the team continually worked to ensure that this dynamic and mindset would guide our interactions with Simoonga.

The team's first meeting with the larger village community was in large part an attempt to introduce themselves as enthusiastic yet inexperienced students, ready for the villagers to take the lead in the project implementation process. 108 interested residents of Simoonga attended this meeting. (See Fig 3) Members of the team introduced themselves and explained how their relationship with Simoonga came to be. They then proposed a design for the VIP latrines that the village was hoping to build.

Before arriving in Simoonga, it was difficult to make direct contact with community 
members by email or phone call. Most communication was relayed through this third party employer of the local NGO. Thus, the team was able to come up with a preliminary design for the VIPs based off of this communication. Upon presenting the design, it was up to community members to discuss it and make changes to the model. (See Fig 4) In order to cater to meeting attendees who did not speak English, the village secretary acted as a translator for this presentation. Following the brief presentation, meeting attendees made numerous suggestions for size, orientation of male and female rooms, and whether or not bathing rooms in addition to the latrine rooms were necessary.

By the conclusion of the meeting, eight attendees came forward as construction professionals. These men who made many suggestions for the latrine design would be instrumental in the coming weeks as leaders of latrine construction. Certain women had also come forward as volunteers to prepare lunch for those working at the construction site. The team had proposed to provide these food supplies if villagers would be willing to cook. While the food served as incentive for volunteers to work on the project, cooking the food also provided an active role for women in the project, who would not traditionally be involved in the construction. The overarching desire on the part of the team was to promote an atmosphere where volunteerism was welcomed, and community members encouraged to take control of as many aspects of project implementation as possible.

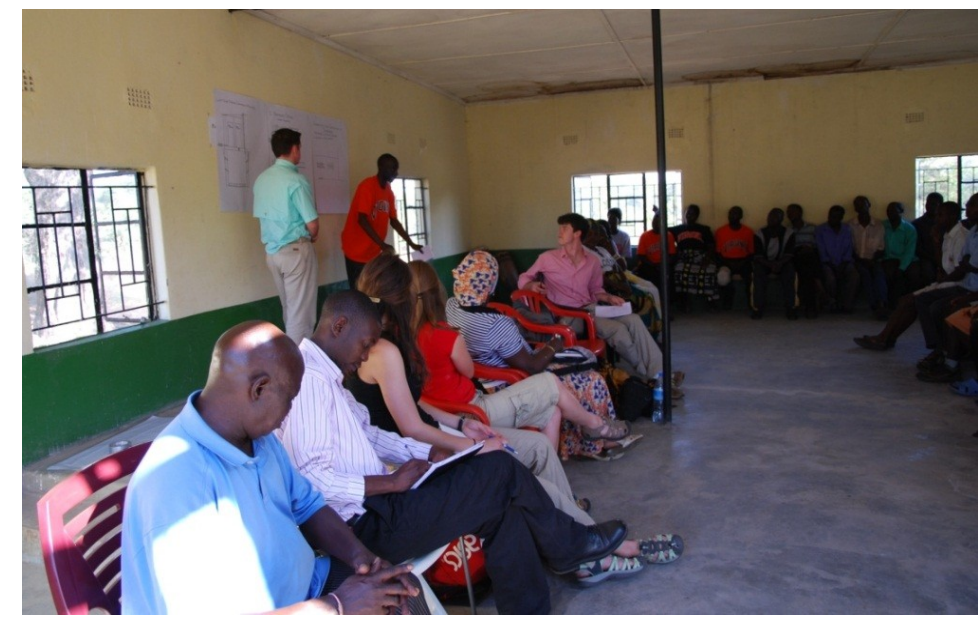

FIGURE 3

The Team Presents the Latrine Design at the First Community Meeting 

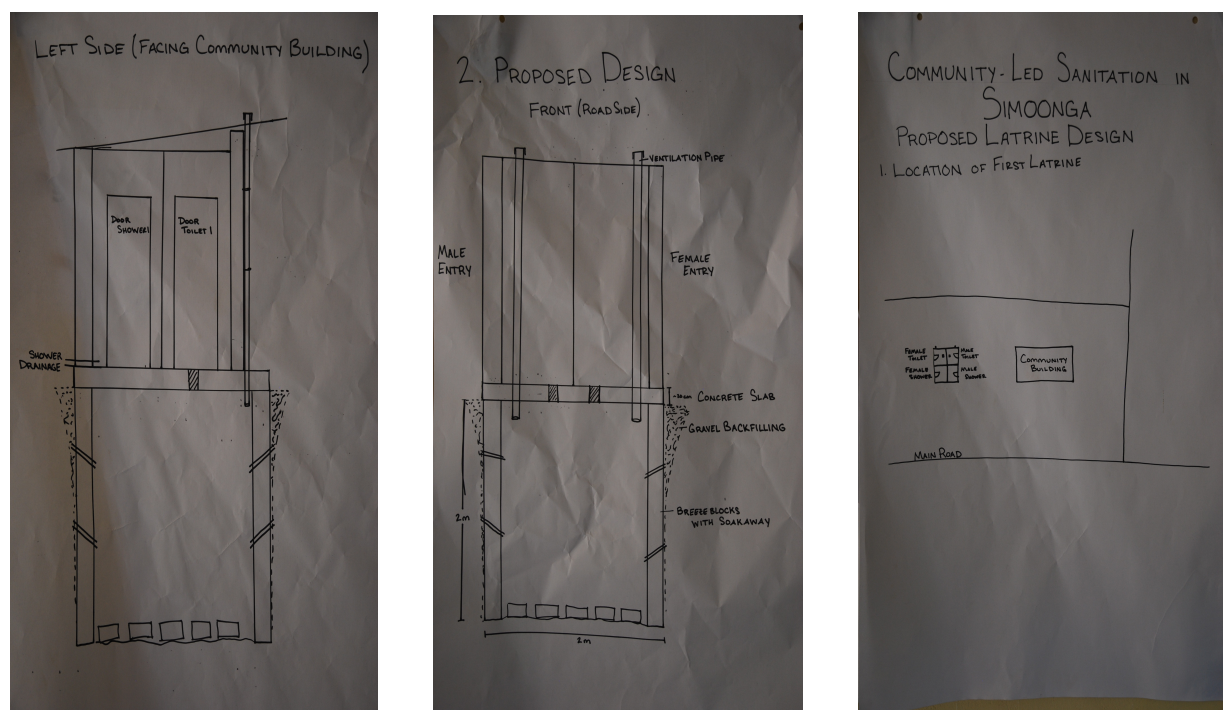

FIGURE 4

Original Latrine Designs, As Presented to the COMMUNity

\section{Identifying Volunteers}

As mentioned, technical experts such as bricklayers, carpenters, and those with other construction experience led day-to-day activities at the work site. The team did their best to make clear that any donation of time and labor on behalf of the experts was on a volunteer basis. The students were very upfront that they lacked the funds to compensate workers. All of the project funds were budgeted for materials so as to construct as many latrines as possible. However, as stated, a free lunch would be provided to volunteers in exchange for a day of work, and a certificate would be given at project completion to present to potential employers as part of their resumes. Our team also hoped that though the workers were not being monetarily compensated, that they would feel some sense of satisfaction from contributing to the development of their own community. The community might not have possessed the financial capital to build communal latrines, but they certainly had the human capital necessary for such a task. With this volunteer-based system, the project thrived on the existing expertise and human capital of community members. However, this is not to say that this system of volunteerism was readily embraced by all Simoongans interested in the project.

Chambers states as one major problem with project implementation the fact that the visitors never really stay around long enough get to know the real village. What the outsiders often see is the village parading its ceremonial face. He describes this dynamic between rural people and visitors in stating, "whatever their private feelings, $[\ldots]$ the rural people put on their best face and receive the visitor well"xiii. Our initial meeting with the village would be an example of a 'best face' moment. Though the team did try to be very transparent about their funds and intentions for assisting in a project that was overwhelmingly a community-led initiative, some miscommunications did occur. It seems that some of the team's intentions were lost in translation, and certain volunteers were under the impression that they would receive 
monetary compensation.

The team discovered this after the first day of construction. On the first day, so many volunteers turned out to help work that there was not enough work to go around. Such numbers were welcomed, though quite unexpected. Thus the team made sure to check with those who had translated the initial meeting if these workers were aware that they were volunteering. It became clear that the message was perhaps not entirely clear to some. Our team attributes this confusion partially to the fact that translators wanted the community good impression and wished for many community members to show up to work. Therefore, they might not have stressed the points about volunteerism in the initial meeting.

Before events progressed any further, another meeting was held to make sure that workers knew it was not possible to pay them. The team also expressed their hope that the volunteers would still stay and take part in constructing these latrines for their community. The next day, the number of volunteers was significantly reduced. However, the remaining volunteers were entirely aware that they would not receive monetary compensation, and were willing to commit their time and effort nonetheless. Fortunately, many of the volunteers with construction expertise had remained. The team was very happy with the remaining volunteers, all of whom continued to work every day for the next six weeks. Over the course of the project, a few of these initial volunteers would stop by to contribute from to time as well.

\section{Construction Steps}

While there were some slight differences between the two latrines built during this project, the construction process was essentially the same. First, team members and volunteers dug a square pit 2 meters on each side. The sandy soil made digging relatively easy but also contributed to a high number of wall collapses. The design originally called for a depth of three meters for a greater pit volume, but as collapses became more frequent beyond a depth of 2 meters, the pits were instead left between 2 and 2.5 meters deep. Both pits were completed in about one half day.

After the pit was dug and the soil cleared out, volunteers poured the latrine's bottom slab, which provided foundation support to the structure. The area on which the slab was built was lined with black plastic, and wood planks were nailed together and used to create a frame into which the concrete would be poured. This was local expertise we did not possess. All of these materials were obtained from two markets in Livingstone. Experts led trips to Zimbabwe Market and Dambwa Central to orchestrate these transactions with trusted suppliers.

The bottom slab was shaped as two concentric squares, with the center square left open for the pit. (See Fig 5) Deformed iron bars were then placed in a pyramid structure, which was laced by brick-force wire to make the slab stronger. (See Fig 6) Concurrently, concrete was made from a mixture of cement, river sand, crushed stones, and water. The mixture was poured into the frame and left to set for several days. 


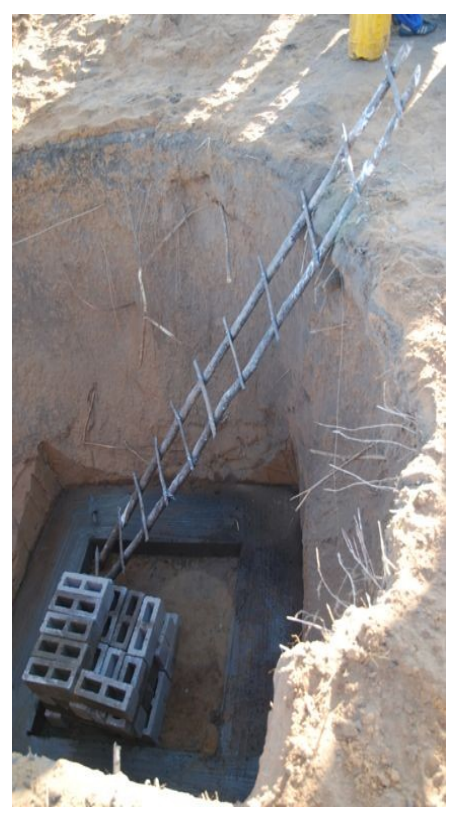

FIGURE 5

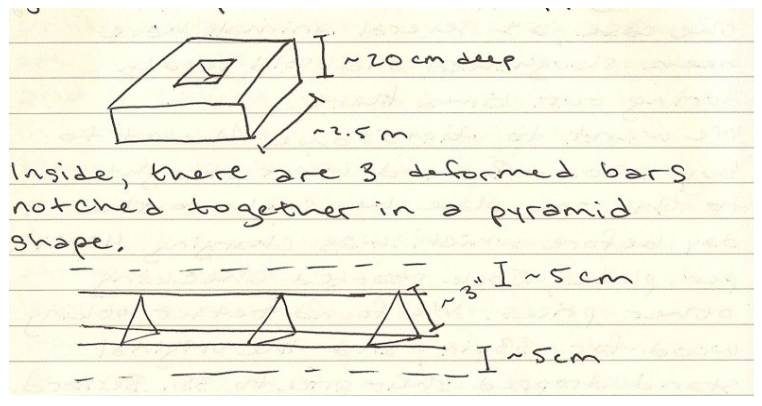

FIGURE 6

BotTom Slab InSIDE FIRST PIT

\section{SKETCH OF REINFORCED SUPPORT INSIDE BOTTOM SLAB}

After the bottom slab had set, the wooden frames were removed and bricklaying paper was placed atop the slab where the walls would be built. The bottom walls of the structure were then built using layers of concrete blocks and mortar made from cement, river and pit sand, and water. There were 12 levels of concrete blocks, rising to a height of 2.5 meters. Brick-force wire was placed every three or four levels to increase the strength of the structure. Soak-away spaces were left open on three levels of two sides of the structure; these spaces were later partially filled in with rocks. This design allows liquid to seep out of the structure. (See Fig 7). 


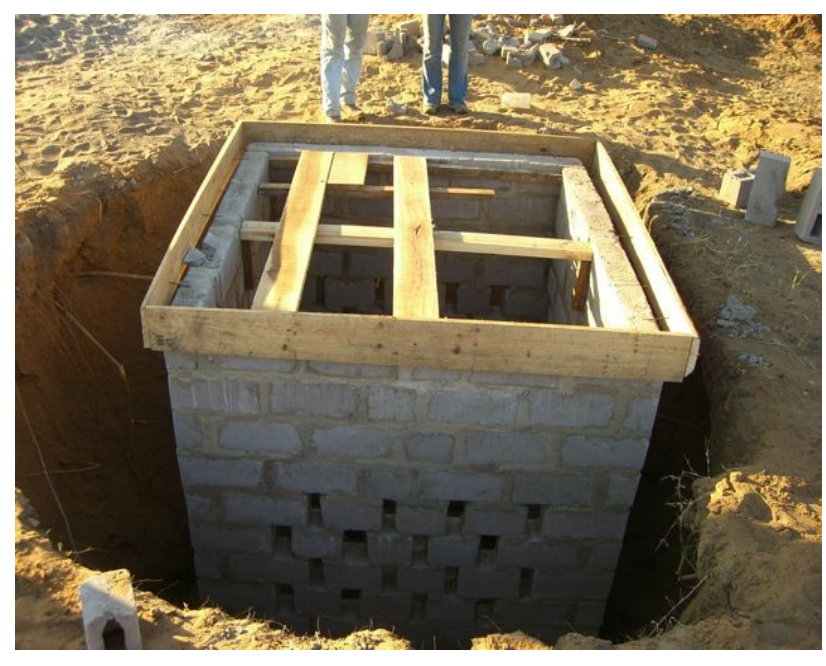

FIGURE 7

\section{Base Pit Structure With Soakaway Holes}

In the absence of a mixer, cement was mixed on the ground using shovels. Sand was first piled into a circular plateau, and cement was spread across the top. The mixture was then mixed thoroughly and formed into an elevated ring. The water was poured into the space created inside the ring, and a team of three circled the ring with shovels, continually mixing a small amount of the external ring into the inside. In this way, the water was contained inside the mass until thoroughly mixed. (See Fig 8) The team considered building the concrete blocks as well, but after consulting with the volunteers, and meeting with a community member who possessed the necessary brick molds, it was decided that it would be too time-consuming. Furthermore, the cost of the molds and materials were as expensive as simply purchasing premade blocks. We would adopt the option of purchasing premade blocks. 


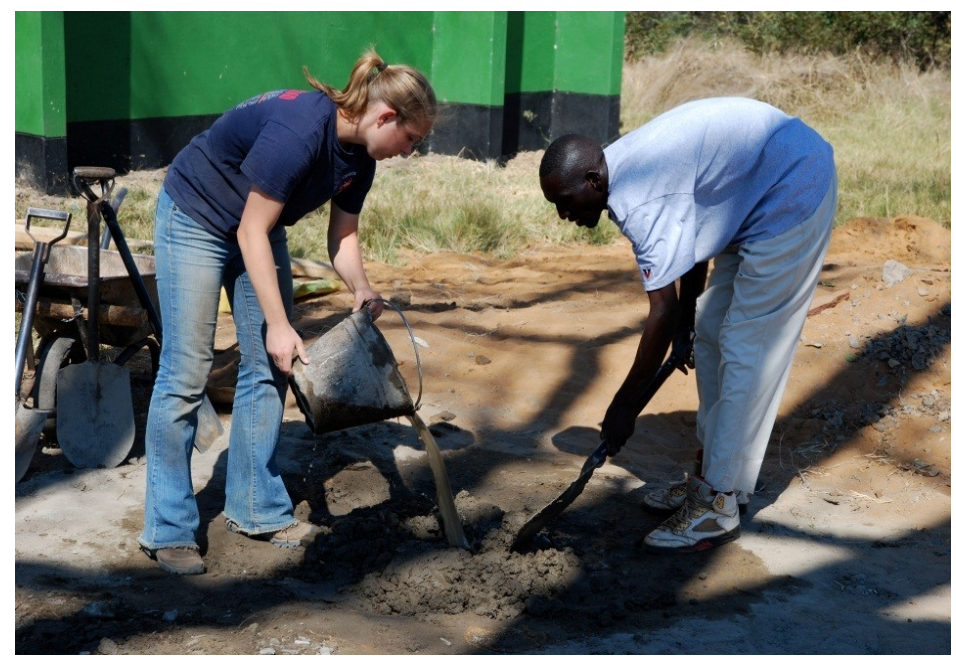

FIGURE 8

Team Member and Community Volunteer MiXing Cement For Mortar

A floating concrete slab was built upon the structure walls. Wooden slats covered with black plastic served as a temporary floor upon which the concrete was poured. (See Fig 10) A hole was left in this temporary floor which concrete was poured around. Once the concrete set, the wooden slats were removed through the hole. By doing this, the wooden floorboard could be conserved and reused for each construction. Two holes were left in the slab around which concrete blocks would later be positioned to create two toilet holes and seats. The holes into which the ventilation pipes would go into the pit were carved out of the concrete after the slab had set. (See Fig 9) As with the bottom slab, wooden planks served as an outer frame and the concrete mix was strengthened with rebar set horizontally and vertically in the frame. 


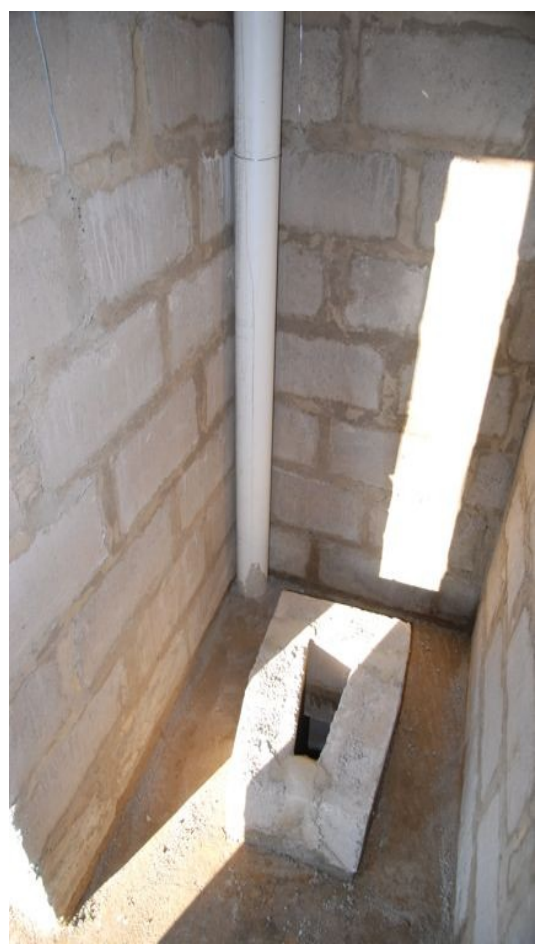

FIGURE 9

FORMED SEAT AND VENTILATION PIPE

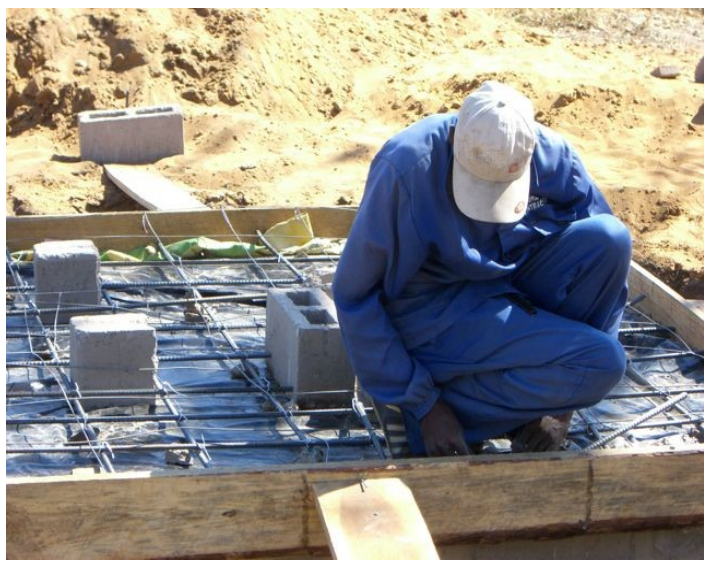

FIGURE 10

Preparation of FloAting Slab

The structure's top walls were built in a similar manner to the bottom walls. However, there were no holes in the walls, two sections were left open for doors, and there was a dividing wall in the center of the area to separate the male and female sides of the latrine. One wall was also built a level higher than the rest so that the roof would be slanted.

Wire mesh was put on the top of the ventilation pipes to stop flies from traveling out from the pit and potentially spreading disease from the waste. Wooden planks were placed along the top wall, center of the structure, and back wall. Iron sheets were placed on top of these wooden planks and tied down with wire. Door frames were built out of wood, and doors were built and set on hinges into the door frame. The structure and doors were painted, and the hole backfilled with rocks and leveled out with sand. Volunteers painted the latrine's date of completion and "Built By the People of Simoonga" in English on the first latrine (See Fig 11) and the same phrase in siLosi, "Iyahilwe ni batu basimoonga," on the second latrine. (See Fig 12)

After the first latrine was built, all members of the community were invited to assess the structure. (See Fig 13) After receiving feedback from this assessment, the team built the second structure, applying several of the suggestions including adjustments to latrine dimensions. These suggestions did not alter the fundamental design of the latrine; rather, basic dimensions were altered based off of critique by community members. 


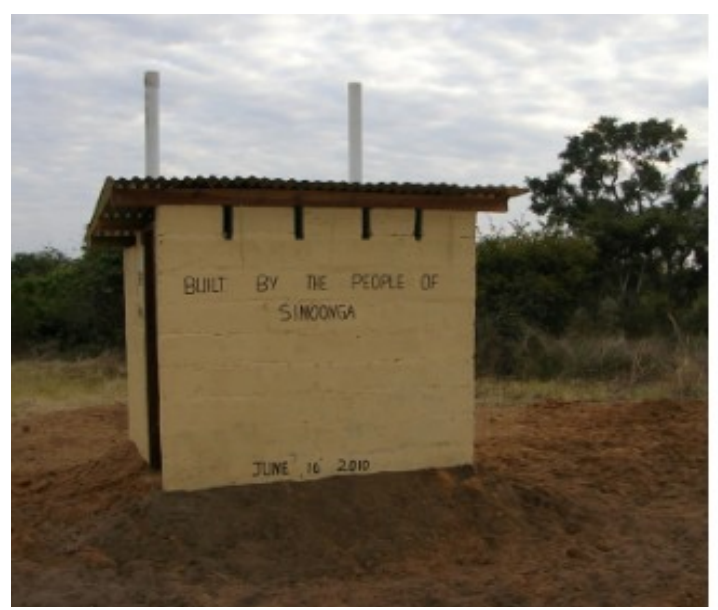

FIGURE 11

FIRST COMPLETED LATRINE

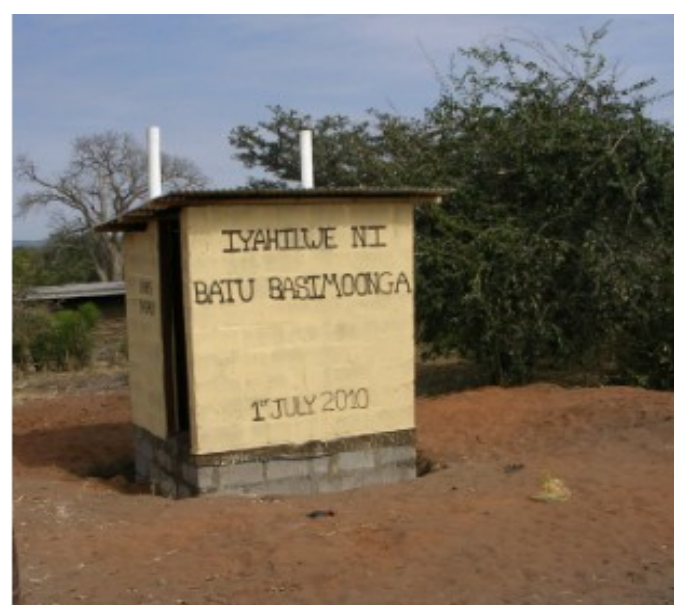

FIGURE 12

SECOND LATRINE

\section{Construction Challenges and Resolutions}

During the project implementation, the team noted a political and social hierarchy in the village. This hierarchy created a situation where access to certain resources seemed to be limited to influential community members. It appeared to even be the case with the existing resources that had been donated to the community - where only those who were related to political hierarchy appeared to have access. This was the case for the town hall, fuel for the water pumps, and a donation of wheelbarrows and construction supplies. The project's communal latrines were expressly designed to provide wider access to all members of the community. In the process, it appeared that this intervention acted to counteract that hierarchy and benefit the entire village as opposed to a few select members. Certain events marked occasions in which this hierarchy was challenged. For example, the team purchased locks to be placed on the inside of the bathroom doors for user privacy. However, when the first latrine was built, the local carpenter placed the locks on the outside of the doors as directed by a representative of the village Headlady. Thinking this to be a simple miscommunication, the team noticed this the next day, removed the locks, and installed them on the inside.

Conflict arose when the finished first latrine was then presented to the community for evaluation. Some villagers - especially the Headlady and village council members from her side of the community - protested that the locks should be placed on the outside. Otherwise, they said, anyone could use the latrines and they would never be clean. The team realized they had perceived locks simply as privacy mechanisms, while certain village members saw them as fulfilling other uses. Some of these politically influential village members had perceived locks as granting exclusive privileges to use the latrine.

The team explained its thought process that the locks would provide privacy for users; an important aspect previously discussed in the community meeting, but not used to keep people out. Since the people of Simoonga had come together to construct these latrines as a communal project, we intended for the latrines to be open to anyone to use at any time. As this discussion played out during the village assessment of the newly constructed latrines a number of villagers 
became vocal about proposing a cleaning system for the latrines where those living close by would rotate maintenance responsibilities. This greatly allayed fears that public use of the latrines would mean that they would deteriorate quickly.

Once a majority of community members at the assessment seemed pleased with the proposed cleaning system and interior locks, the meeting began to disperse. Only a few unhappy parties remained - those who would have been in possession of the keys for unlocking the latrines.

At this point in the project, the team had learned of the Headlady's close relationship with local resort lodges who had conducted projects in the past. Many of these supposed communal projects had come to be looked at as the personal possessions of the Headlady. This was perhaps most evident by the case of the boreholes, where fuel to pump the water was first sent to the Headlady's house, followed by the basic school, and police station, and only then if any was left, to the boreholes used by average villagers. This had caused some resentment among community members, especially those living on the Headman's side of the village.

The team surmised that if the latrines were locked from the outside, and the key was left in the possession of the Headlady and her affiliates, the latrines would essential become another one of her possessions. These structures that were meant for public use and for the good of the community would then be left locked indefinitely and be of little use to residents.

The team was pleased by the community discussion that led to the decision to keep the latrines unlocked from the outside. It seemed that the residents of Simoonga village were ready and excited to accept ownership of their first public structure that was open for all to use but also the responsibility of all to upkeep.

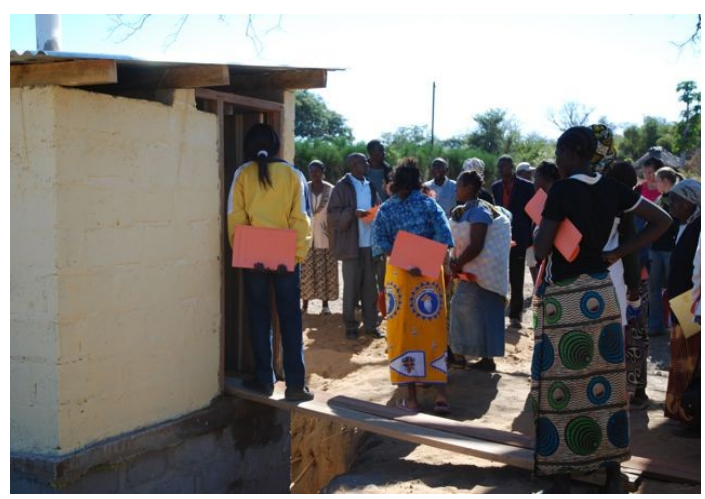

FIGURE 13

COMmunity Members Gather to Assess Initial LATRINE STRUCTURE

An instance of the conflict between the team's priority for quality and the villagers' priority for quantity arose during the backfilling phase. The original design of the latrine required that the space between the latrine structure and the pit be fully backfilled with rocks. Given the time necessary to gather, transport, and fill this quantity of rocks and crushed stone into the hole, the villagers wanted to hasten the process by either partially backfilling the latrine structures with rock, or by backfilling with dirt rather than rocks. Quickly finishing this process would mean that construction could commence on another latrine. The team opposed these ideas, as replacing rocks with a less stable dirt medium would severely decrease the structural soundness of the latrine and increase the risk of wall collapses. Backfilling with rocks is necessary so that there is 
a porous medium surrounding the latrine. This porous medium allows for effective liquid dispersion from soak-a-way holes while supporting structural integrity by holding back surrounding earth. In the students' opinion, the increased speed came at too high a cost to the soundness of the latrine. Construction stalled as the team wished to wait for rocks to backfill, and the villagers wished to backfill with dirt. Ultimately, both groups compromised that the hole would be backfilled with rocks to an agreed-upon level that exceeded the height of the shallowest soak-a-way holes and then filled in with dirt. A truck was procured to gather and transport rocks, and volunteers placed these rocks into the hole.

The subject of materials was another contentious issue. The team's estimate for the amount of materials needed sometimes differed markedly from the experts' predictions. For the first latrine, the team followed the experts' predictions. However, it became clear midway through this first construction phase that more and more items were unaccounted for as time went on. Some of the materials purchased, such as crushed stones and cement blocks, were not able to be practically secured overnight and were thus left out at the construction site. Moving these materials back and forth between the town hall and the construction site, which was used to lock up the other materials, and the construction site would have required an extraordinary amount of extra effort that could have been well spent elsewhere. These unattended materials were sometimes carted away afterhours by opportunistic residents. More cement blocks and crushed stones had to be purchased halfway through the construction of the first latrine due to these circumstances.

Upon beginning work on the second latrine, the team communicated to all the experts and volunteers assisting in construction that no additional materials could be purchased. The team's funding was spent, and the current supply of materials had to be sufficient to construct the second latrine. From this point on, the team did not notice any significant quantities of materials going missing. This could have also been aided by the fact that the construction site for the second latrine was directly surrounded by a number of villagers' houses who could monitor the area. The first latrine was not as close to villager housing, and located in a more public space near the town hall. Centrally located at the front of the village, this location was out in the open and saw much foot traffic. Materials left here were much more vulnerable to being carried off by passersby.

\section{REFLECTIONS \& CONCLUSIONS}

The team worked in Simoonga for six weeks. One tangible product of their efforts was the construction of two latrines. However, upon arrival the team members spent a full week in the village area without touching any construction materials. In that first week, they held meetings with partners from Lusaka, Livingstone, and Simoonga. These meetings allowed the team to hear from varying perspectives about the culture, community, and existing projects. This time was also spent strengthening existing relationships that had begun over the phone and through email, and seeking out new partners to further develop connections to the community.

The need for improved sanitation coverage was expressed by villagers, and the necessity for better sanitation was nearly universally recognized by the community members. Volunteers from the community were a driving force in the construction, some materials were donated by community members, and local experts served as leaders and champions of improved sanitation. Multiple nearby tourist lodges have built several new buildings for the community, including a 
town hall, police post, medical clinic and water generator station. The tourist lodges pay professionals from the nearby city of Livingstone to perform this work. These projects, while quickly executed, often fall into disrepair and do not seem to be utilized or maintained by community members. The efforts of these lodges are very well intended, and the team hoped to learn from their observations of existing projects.

While the team had hoped to build more than two latrines, they also believed that the quantity of structures mattered less than the quality of work and the general acceptance and ownership of the project by the local community. Additionally, principles aside, the length of time spent on each latrine was also affected by local provision of materials. For instance, the transportation of stones for backfilling required an unpredictably large amount of time. Several delays were also associated with acquiring local goods and materials, such as sand and wire mesh. The team dedicated a great deal of time to developing relationships and ensuring that the community was involved in the design and implementation process. As a result of this, the team and community members were able to work together to address problems that arose such as the delays in procuring stones for backfilling and the later issue of locked latrines.

One significant outcome, which also indicates a new openness to the concept of communal ownership, is the creation of a sanitation committee. While the team was present in the development of this committee, it was instigated by community members who had volunteered their time during the construction process. The sanitation committee is a coalition of male and female villagers from both sides of the village and is led by one of the lead building volunteers. The committee organizes maintenance of the latrines and promotes improved sanitation practices through education and awareness of sanitation issues, encouraging use of the latrines, and raising funds and support for more latrines.

Throughout this entire process, challenges were encountered in many areas such as dealing with communication, building logistics, and village politics. However, in confronting these challenges, the team stayed true to their original project philosophies. Encouraging community contribution and volunteerism, and creating structures that the community would recognize as products of their own hard work were always top priorities. The team hopes that the completion of the two VIP structures and formation of the sanitation committee mark a beginning to what will be a long standing strategy in Simoonga of improving communal sanitation.

As the team left Zambia, and Simoonga, in particular, it would look back on six weeks of learning. The first lesson learned has to be that community engagement takes time and is negotiated throughout project implementation as new issues and ideas begin to emerge. Another fact is the recognition that all politics is local. It is local realities that should guide project conception and implementation. Furthermore in the course of project implementation it is essential to step back and allow the beneficiaries to exercise agency which should be about them. This way people feel empowered enough to take control and ensure sustainability of the project. On the first day we saw the 'best face' of Simoonga. We stayed long enough to get to know the real face and help implement a project that was unique for this relationship. 


\section{REFERENCES}

i "UNICEF - Water, Sanitation and Hygiene - UNICEF Water and Sanitation." UNICEF - UNICEF Home. 6 July 2010. Web. 28 Aug. 2011. <http://www.unicef.org/wash/>.

ii United Nations. "Water for Life, 2005-2015 International Decade For Action: The Global Sanitation

Situation.” 2005. Web. <http://www.un.org/waterforlifedecade/factsheet.html>

iii Berger, Iris. South Africa in World History. New York: Oxford Univ., 2009. Print.

iv Berger, Iris. South Africa in World History. New York: Oxford Univ., 2009. Print.

$\checkmark$ Berger, Iris. South Africa in World History. New York: Oxford Univ., 2009. Print.

vi Mara, Duncan. The Design of Ventilated Improved Pit Latrines. Rep. Vol. 13. Washington, DC: The International Bank for Reconstruction and Development/THE WORLD BANK, 1984. Print.

vii Community-Led Total Sanitation. Institute of Development Studies, 2008. Web. 15 Oct. 2009.

$<$ http://www.communityledtotalsanitation.org/ resource/handbook-community-led-total-sanitation>.

viii National Sanitation Task Team, Department of Water Affairs and Forestry. "Sanitation For A Healthy Nation: Sanitation Technology Options". South Africa, 2002.

ix Heil, E., Nengwenani, D., Raedani, A., Gutierrez, V., Nthambeleni, G., Mathoma, K., Brown-Glazner, R., Swap, R. Student-led, Community Driven Improvement of the Drinking Supply in a Rural Village in South Africa. International Journal for Service Learning in Engineering, North America, 5 May 2010. Web.

$<$ http://ibrary.queensu.ca/ojs/index.php/ijsle/article/view/2230>.

${ }^{x}$ National Sanitation Task Team, Department of Water Affairs and Forestry. "Sanitation For A Healthy Nation: Sanitation Technology Options". South Africa, 2002.

${ }^{x i}$ Rossi, B. 2006. 'Aid Policies and Recipient Strategies in Niger: Why Donors and Recipients Should Not Be Compartmentalized into Separate "Worlds of Knowledge", in D. Lewis and D. Mosse (eds) Development

Brokers and Translators: The Ethnography of Aid and Development. Bloomfield: Kumarian.

xii Cornwall, Andrea and Nyamu-Musembi, Celestine (2004) "Putting the 'rights-based approach' to development into perspective", Third World Quarterly,25:8,1415 - 1437

xiii Chambers, Robert. Rural Development: Putting the Last First. London: Longman, 1984. Print. 